\title{
Correction to: Notes on the typification of four Himalayan aconites
}

\section{Priyanka Agnihotri $^{1,2}$, Danish Husain ${ }^{1,2}$, Pushpendra Katiyar ${ }^{1}$ \& Tariq Husain ${ }^{1,2}$}

A Correction to this paper has been published: https://doi.org/10.1007/s12225-021-09976-x

\section{Correction to: KEW BULLETIN (2016) 71: 52}

https://doi.org/10.1007/s12225-016-9666-1

As a prerequisite to include the Ph.D. awarding University affiliation for the award of a Ph.D. degree, an affiliation for the scholar and Ph.D. supervisor has been added to this article (see the footnotes below).

The original article has been corrected. 